\title{
Let the games begin: Finding the nascent entrepreneurial mindset of video gamers
}

\author{
Thomas Niemand \\ TU Clausthal \\ thomas.niemand@ \\ tu-clausthal.de
}

\author{
Stephanie Scott \\ Durham University \\ Business School \\ s.a.scott@durham.ac.uk
}

\author{
Sascha Kraus \\ Durham University \\ Business School \\ sascha.kraus@durham.ac.uk
}

\author{
Raphael Oberreiner \\ University of Liechtenstein \\ raphael.oberreiner@ \\ hotmail.com
}

\begin{abstract}
This study explores nascent 'entrepreneurial' cognitive factors within the minds of video gamers. The objective is to theorize how certain gamification activities might be designed to enable the development of entrepreneurial behavior. While studies have begun to posit the range cognitive factors that result in the emergence of entrepreneurial action, more conceptualization work is needed to understand nascent conditions and activities that might foster the entrepreneurial mindset; especially within the gaming design context. This exploratory study uses a sample of 217 self-reported gamers and suggests that individuals who exhibit high levels of entrepreneurial orientation have enhanced opportunity recognition capabilities when the frequency of playing video games is also high. It was also found that shooting games have the highest effect on the development of opportunity recognition. This suggests that certain game activities may be designed to enhance entrepreneurial cognitive development; which has implications for the entrepreneurial intent literature and game-designers.
\end{abstract}

\section{Introduction}

There has been an increasing interest to embed and develop a strategy for gamification in firms [32;69]. Gamification is the use of various activity design mechanics and components that mimic play behaviors into non-game contexts [12]. The premise is that mundane non-game activities can be transformed into a more playful and self-directed activity to encourage the development of desirable skill sets and behaviors [53]. The transition to this 'playful' process has been lauded by a variety of outlets for motivating changes in human behavior across varying contexts; including healthcare, consumption, consumer engagement, and a range of training/pedagogy activities [2;33]. This is because conversion to a new contextual environment provides the opportunity for task designers to draw on theories of the self-determined motivational draw to encourage sustained engagement, as individuals (users) are more likely to enjoy the pursuit of self-imposed performance optimization and mastery than they are to be externally mandated $[35 ; 65]$. As a result of the engagement, players may be intrinsically motivated to engage and can gather iterative learning opportunities across contexts [63]. Therefore, the opportunity to strategically employ the design principles of gaming offers a promising new model for driving positive outcomes [56]. Of interest, is how organizations may use this technique to embed behaviors and skillsets within the training of their employees [47; 64] and, thus, to enhance organizational productivity [55]. Yet, the research on these regulatory processes and how games can be designed to drive a specific set of outcomes remains relatively fragmented within the literature [69].

Gamification is still an emerging topic within organizational studies [69], but there has been some evidence that it can provide favorable conditions to develop certain organizational behaviors; including enhanced administrative control, processing speed, attention control, and spatial ability [25; 60]. Similarly, other studies, in associated research domains, also suggest that playing video games influences personality development and overarching academic performance $[68 ; 73]$. When applied within the business pedagogy setting, a recent experiment using game-based computer simulations suggested that 'gamifying' specific contexts provide opportunities for players to conceptualize concepts that are difficult to grasp; such as organizational culture and the practical usage of strategic resources [51]. Further studies have begun to link game attributes to cognitive development, as evidenced in a recent meta-analysis of game research and impacts on cognition [73]. However, more research is needed to understand how a player can extract specific lessons out of a game and, 
given the variety and complexity of computer game activities available, which gaming-design environments enable certain forms of behaviors or cognitive skills to emerge $[64 ; 74]$.

The ability to behave entrepreneurially is a desirable skillset that many managers hope to foster within their organizations and employee base [27; 29]. Firms are keen to develop programs the enable individuals to identify and create new markets [8] and, thus, the entrepreneurial gamification concept is an important area to explore. However, the design features of such a game are likely to be a challenge. As an example, authors frequently debate if the entrepreneurial mindset is even a learnable skill [10; 40 ; 49]. To be entrepreneurial requires the individual/firm to be innovative, creative, proactive, and risk-taking $[37 ; 38]$ which are often associated as soft skills that can only be established through experiential learning. On that account, using strictly forward methods and rote learning modes to embed entrepreneurial skills may not be appropriate. However, this requires further exploration. Notwithstanding that entrepreneurial skills may be trained by games in the long-term, establishing a theoretical and empirical link between gaming and entrepreneurial skills is necessary. Additionally, is it possible that entrepreneurs may be more prone to gaming, and can this be the first prerequisite to investigate this link in a causal manner?

This study contributes to the gaming and work process literature by transcending the need to understand motivation and engagement factors; and, thereby, focuses on how the desired behavioral outcome may emerge. Two research questions guide it. First, the study asks, does the intensity of playing video games increase the likelihood for entrepreneurial orientation (EO) to develop in individuals (risk-taking, proactiveness, innovativeness)? The second examines if the concentration of playing video games, when coupled with EO characteristics, can lead to the better manifestation of individual cognitive skills associated with entrepreneurship; precisely, opportunity recognition? To explore these questions, the study begins by reviewing the organizational gaming literature. This section emphasizes that while some work has occurred, the current body of research falls short of providing explanations into how work process games can be designed for the development of entrepreneurial behavior. The paper then moves to elucidate theories of the entrepreneurial mindset. Through reviewing this notion, it becomes apparent that two different cognitive domains should be considered; the psychological features of entrepreneurial orientation to characterize attitudinal dimensions (risk-taking, proactiveness, innovativeness) and the cognitive ability to recognize opportunities; which provides the theoretical foundations of the study.

\section{The Gaming Organization}

Over the past ten years, there has been an explosion of interest in the potential for gamifying behaviors. Organizations have been keen to adopt an approach to engaging individuals through various game-like activities [17]. Most authors on the subject agree that game-based learning and work processes can transform the typically mundane and extrinsically regulated behaviors to more self-directed and intrinsically motivated activities $[55 ; 57]$. However, trends within the literature have primarily focused on the motivational draw and how design elements can be integrated to encourage continued engagement within a given platform or activity [47; 69]. Understanding the psychological aspects of continued commitment within a given platform and the use of play mechanics are essential to understanding how to design the activity, but this is only one aspect of the puzzle [30]. Questions remain as to what extent the overarching and intended lessons are being achieved, and how certain organizational behaviors or cognitive skills can be enabled in such an environment.

As gaming platforms are increasingly being used as an outlet for human resource development or the promotion of broader organizational behaviors [11], there remains a significantly gray area within our understanding on how these activities can be designed to effectively disseminate soft skills and/or normative organizational behaviors that influence long term work processes and productivity [20]. The motivation to sustain engagement is well debated within the realms of motivational research. However, it is also well recognized that this engagement typically wains after a short period [64]. Some authors suggest that benefiting from gamified work processes requires an understanding of individualistic perceptions and the meanings they ascribe to the experience [65] yet; there are fewer studies that focus primarily on the natural learning objective and desired output.

\section{The Entrepreneurial Mindset}

Of interest to this study is to what extent gaming can foster the manifestation of entrepreneurial behavior and cognitions. Understanding the entrepreneurial mindset is essential to distilling the ways that 
individuals perceive and react within their environments to create new opportunities [14]. The entrepreneurial mindset can be defined as a field of study that aims to understand the cognitive skills and attitudes that an individual possesses to sense and seize business opportunities [34]. It is well accepted that it is an essential element of new venture creation [72], however the cognitive determinants that drive this process are widely debated and researched. For instance, there are streams of research that focus on the psychometric profile [62], motivations [39], pedagogy [41], and processing abilities [5; 6]. The main thrust of this work is to understand how entrepreneurs might develop the cognitions to be active within this domain.

Additionally, individuals who are embedded within entrepreneurial organizations will have varying mindsets that allow them to be more effective than others [38]. These individuals, embedded in the microeconomic layer, will influence firm-level performance. While research has begun to explore entrepreneurial cognitions on this level, more work is needed to understand how and in what ways these cognitions are developed, precisely so that activities and games can be designed for learning opportunities. To the researcher's knowledge, the use of gamification or gaming applications to enhance or develop the entrepreneurial mindset has not yet been explored.

Much of the research on the individual entrepreneur focuses on collecting data following successful instances of entrepreneurship [23]. When attempting to collect data on the factors leading to entrepreneurial outcomes, they are met with a methodological challenge as the entrepreneurs report their perceptions of factors that resulted in the emergence of their entrepreneurial success. Yet, it is essential to understand the attitudes and beliefs that led to the manifestation of entrepreneurship. The nascent conditions, in which the entrepreneur possessed before they engage with new ventures, will still likely have an 'attitude' towards entrepreneurship and some of the cognitive skills. However, most work in this area focuses on active entrepreneurs and their attitudes within the process of planning a current venture [40]. To better understand these conditions, research must be designed to assess varying contextual environments.

\section{Individual Entrepreneurial Orientation}

The theory of entrepreneurial orientation (EO) serves as the theoretical basis for this study. It was initially designed to characterize firm-level abilities to create new ventures and markets [43]. The entrepreneurial orientation model is a collection of psychometric scale items used to describe and predict the manifestation of entrepreneurial activities from the firm level $[38 ; 48 ; 54]$. Typically, the high values in each of the entrepreneurial orientation dimensions are desirable but vary in prevalence across firm [16]. The construct has proven to be useful in research and practice for characterizing firms across industrial and strategic contexts; and precisely, for describing the levels of risk-taking, proactiveness, and innovativeness of firms [40]. However, the collective understanding of the firm-level construct is that organizations are highly varied across each of these dimensions.

Debates have emerged over the validity of a single construct at the firm level, insomuch that it may have diluted a far more complex sociological and psychological process. In acknowledging the potential oversimplification, the methodological framing of the construct has been more explored and applied to the individual/micro-level components of the firm [29]. As such, recent work has begun to explore the entrepreneurial dimensions beyond the firm-level and have applied the scale items to the individual level [23; 37]. The central premise behind this work is that the individual agents, embedded within the social structure, have a mutually reinforcing influence on the overarching economic performance of the firm. In acknowledging the individualistic role agents play, the original model has been extended, refined, and tested to postulate a broader range of cognitive factors that drive entrepreneurship. For example, research has suggested that an individual entrepreneur is tolerant of ambiguous situations, prefer autonomy, resist conformity, enjoy risk-taking, and adaptable [61]. Thus, these findings suggest that the EO model may require some modifications and further empirical testing. Scholars are now keen to identify the various psychological factors that influence this process from an individual mindset point of view. Implicit within this research strand is the notion entrepreneurial behavior is embedded within individual cognitive skills and may emerge over time.

The usage of the EO model (within the context of individual entrepreneurs) provides opportunities for further elaboration for influencing variables, such as the cultural environment, political-legal environment, macro-economic and micro-economic environment $[36 ; 37]$. This has resulted in the identification and usage of the opportunity recognition construct as a critical cognitive skill that could be aligned with the EO model. 


\section{Opportunity Recognition as a Cognitive Skill}

Opportunity recognition is increasingly recognized as a cognitive skill that entrepreneurs must possess. It is typically understood as the ability to recognize or perceive opportunities to create new markets, products, and services $[4-6 ; 26 ; 44 ; 70]$. The field of study aims to understand how entrepreneurs identify opportunities; e.g., "the processes of discovery, evaluation, and exploitation of opportunities" [62]. Within the last three decades, there has been considerable work on opportunity recognition research, but the field is still fragmented and empirically underdeveloped [21]. While a developing area of study, it seems as though the ability to be entrepreneurial is significantly dependent upon the cognitive skill of opportunity recognition $[38 ; 41 ; 58]$. The ways opportunities are recognized, and the identification process has not yet received enough empirical treatment [21-22; 45].

Opportunity recognition is a multifaceted process [7; 13] that relies upon a relationship between discovery and creativity [46]. It requires a cognitive processing capability which blends market information with creativity [28; 45; 67]. It is a subjective and complex process that might be developed within the minds of individuals $[14 ; 15: 71]$, but the work examining the factors that lead to its development remains fragmented. If the entrepreneurial orientation is dependent on an individual's ability to effectively engage in opportunity recognition, and opportunity recognition is a cognitive skill that develops over time $[4 ; 41 ; 66]$, then research should focus on the factors that enable and foster the development of this skilled behavior. Surprisingly, this is an under-researched area in both EO research and within the entrepreneurial education work. This study explores this gap by collecting evidence of the nascent entrepreneurial attitudes and skills embedded within gamers.

\section{Methodology}

This exploratory study was designed using a deductive approach. As the study aims to understand existing models and results within a new context, a quantitative design is the most suitable $[9 ; 24]$. Predetermined methods (sample description, regression analysis, correlation analysis), instrument-based questions (online survey), and gathered data were used for the research. The correlation analysis and regression analysis is grounding on theoretical assumptions of causality, but this causality itself cannot be fully achieved within the scope of this study.
Thus, the research was designed to explore relations among the constructs $[19 ; 42 ; 50]$.

\subsection{Sample}

The participants in the study account for 223 people gathered from the online academic survey platform, "Prolific." Prolific is an innovative start-up incubator company from the University of Oxford, which offer a high-quality participant pool. Participants must fulfill the following requirements to be considered: age above 18 , minimum of three video gaming hours per week, region/country of residence either Europe or the USA. Due to non-completed responses three of the 223 participants have been excluded, another two for providing incorrect answer to a bogus question (respondents were asked to click on a predefined option in order to check whether reading and comprehension took place), and the final one due to playing an amount per week well over 100 hours per week (101.92 hours), resulting in a total amount of 217 valid responses. Out of the participants, there is 57 female $(26.3 \%)$. The average age is 31.42 (standard deviation of 8.02). 59.9\% (130) of the participants have their residence in the United States of America, while $40.1 \%$ (87) live in Europe (including people from Australia, Bosnia and Herzegovina, Canada, Croatia, Czech Republic, Denmark, Estonia, Finland, France, Germany, Greece, Hungary, Iceland, Ireland, Italy, Lithuania, Luxembourg, Malta, Montenegro, Norway, Poland, Portugal, Serbia, Spain, Sweden, Switzerland, Ukraine, and United Kingdom in an alphabetical order). Fourteen genres of gaming were covered ("Please tick those genres, which you are playing more frequently [max. 5]."). Genre role-play games, RPG, $(157,72.35 \%)$ was played on average 18.86 hours per week $(\mathrm{SD}=12.99, \min =4, \max =85)$. The genre of shooter $(134,61.75 \%)$ was second with a 19.65 hours average $(\mathrm{SD}=12.52, \min =4, \max =70)$, followed by strategy $(94,43.32 \%)$ with a 19.11 hours average (SD $=10.18, \min =4, \max =50)$ and simulation $(54$, $28.88 \%$ ) played on average for 23.65 hours ( $\mathrm{SD}=$ $15.96, \min =4, \max =85)$. Finally, the management genre $(49,22.58 \%)$ yielded an average of 19.37 hours played $(\mathrm{SD}=12.18, \min =4, \max =58)$. Overall, the sample seems to be representative for the gaming population, with a lower share of women, a rather young audience and a wide range of hours played over more (RPG, shooter) and less prominent genres (simulation, management).

\subsection{Data Collection}

The approach to developing a valid and reliable questionnaire is a broadly discussed topic in academia 
Table 1. Estimates for the interaction model

\begin{tabular}{|c|c|c|c|c|}
\hline & Model 1 & Model 2 & Model 3 & Model 4 \\
\hline $\begin{array}{l}\text { Variables } \\
\text { included }\end{array}$ & $\begin{array}{l}\text { Gender, age, } \\
\text { education, } \\
\text { profession, residence, } \\
\text { genre } \\
\text { (covariates) }\end{array}$ & $\begin{array}{l}\text { Covariates + risk- } \\
\text { taking, proactiveness, } \\
\text { innovativeness, } \\
\text { intensity } \\
\text { (main effects) }\end{array}$ & $\begin{array}{l}\text { Covariates + main } \\
\text { effects }+ \\
\text { risk-taking * } \\
\text { intensity, } \\
\text { proactiveness * } \\
\text { intensity, } \\
\text { innovativeness * } \\
\text { intensity } \\
\text { (interaction effects) }\end{array}$ & $\begin{array}{l}\text { Covariates }+ \\
\text { interaction effects } \\
\text { only }\end{array}$ \\
\hline $\begin{array}{l}\text { AIC (lower is } \\
\text { better) }\end{array}$ & 646.85 & 443.59 & 459.01 & 361.04 (lowest) \\
\hline $\mathrm{BIC}$ (lower is & 762.39 & 571.09 & 595.34 & 489.47 (lowest) \\
\hline
\end{tabular}

[19; 42; 59]. A well-accepted method of creating a survey is to utilize a commonly used or previously published scale [42]. This approach is well accepted because of its advantage to rely on previously tested scales, which increases the possibility to receive a valid and reliable questionnaire. The questionnaire used for this research is a gathering of previously validated instruments.

The scales for the entrepreneurial orientation dimensions innovativeness, proactiveness, and risktaking are derived from previous studies $[16 ; 18]$. Tang et al. (2012) [66] have developed an instrument to measure one's opportunity recognition by three subscales: Scanning and search, association and connection, and evaluation and judgment. Opportunity recognition yielded a reliability of .92 with all subscales exceeding the Cronbach's alpha threshold of 0.7 [50]. Finally, the intensity of playing games was measured by having respondents indicating the number of hours playing per week ("How much hours do I spend per week for playing video games?"). Since this indicator is concrete and easy to understand, no multiple-item measure was applied [3]. The intensity was log-transformed after that to normalize its distribution (rather chi-square distributed before). All scales and sub-scales showed convergent validity (average variance extracted $>.5$ applying a Maximum Likelihood CFA of all multi-item measures) and were discriminant from each other by utilizing the HTMT procedure [31].

The following covariates were used as control variables: gender, age, education, profession, residence, and the genre respondents preferably played (multiple responses). All categories were coded as dummy variables. The covariates of interest in a study are determined by other similar studies close to the field of interest. For instance, gender impact the proclivity for entrepreneurship [23] control age and gender within their development of the opportunity recognition scale [66]. Within the development of the individual entrepreneurial orientation scale by
Lumpkin and Dess (1996) [43] they were controlling their instrument measurement by education and gender. An assessment about potential linkages from Kreiser et al. (2013) [38] between dimensions of entrepreneurial orientation and cultural aspects led to a conclusion that at least two of the three subscales from the entrepreneurial orientation have strong connections to the cultural environment, hence the country of residence has also been implemented as a covariate. Lastly, the preferred genre of gaming (e.g., classic or action adventures, shooters, simulations or sports games) was controlled to assess differences in the required skills for those genres (e.g., simulations require more planning while shooters and sports games require quick interaction, see [73]).

Past research on entrepreneurial orientation shows that the dimension of entrepreneurial orientation correlates high with each other and the performance measure $[7 ; 39 ; 72]$. As opportunity recognition is crucial to be a successful entrepreneur, this newly introduced performance measure fits well into the entrepreneurial orientation construct, in comparison to the others.

\section{Results}

A stepwise regression approach was applied to derive the influences on opportunity recognition using linear mixed-effect models allowing for random intercepts and individual mean differences of respondents. In a base model (model 1), only the covariates were regressed on the dependent variable. Further, a second model (model 2) adds the main effects of dimensions of entrepreneurial orientation (risk-taking, proactiveness, innovativeness) and intensity to model 1 . Model 3 then investigates the main and interaction effects of intensity and entrepreneurial orientation dimensions. Since the main effects may become redundant, model 4 finally tests interaction effects only [1]. By comparing models with information criteria (AIC, BIC), it is found that model 
Table 2. Estimates for the interaction model

\begin{tabular}{|c|c|c|c|c|}
\hline Coefficient & Estimate & Std. Error & $\mathbf{t}$ & $\mathbf{p}(\mathbf{t})$ \\
\hline (Intercept) & -.67 & .28 & -2.38 & $.02 * *$ \\
\hline \multicolumn{5}{|l|}{ Covariates (control variables) } \\
\hline Genre Classic Adventure & -.10 & .09 & -1.06 & 29 \\
\hline Genre Action Adventure & .09 & .09 & 98 & 33 \\
\hline Genre Arcade & -.05 & .11 & -.47 & .64 \\
\hline Genre Brain Teaser & -.07 & -13 & -.56 & .58 \\
\hline Genre Jump and Run & .08 & 10 & 84 & .40 \\
\hline Genre Board Game & -.12 & .14 & -84 & .40 \\
\hline Genre Children & -.14 & 33 & -.43 & .67 \\
\hline Genre Management & .09 & -10 & 91 & .36 \\
\hline Genre RPG & .09 & .09 & 1.01 & 32 \\
\hline Genve Shooter & 27 & .08 & 3.22 & $.00 * * *$ \\
\hline Genre Simulation & .10 & 10 & 96 & 34 \\
\hline Genre I ifestyle & .10 & 21 & -48 & .63 \\
\hline Genre Sport & -15 & 10 & -1.53 & .13 \\
\hline Genre Strategy & -.03 & os & -.32 & .75 \\
\hline Gender Male & -09 & .09 & -91 & 36 \\
\hline Age & 01 & 01 & 1.48 & .14 \\
\hline Residence Germany & .07 & 31 & 23 & 82 \\
\hline Residence Greece & 20 & 34 & .61 & .55 \\
\hline Residence Hungary & .00 & 30 & .00 & 1.00 \\
\hline Residence Poland & -.34 & 30 & -1.11 & 27 \\
\hline Residence Portugal & 22 & 35 & .64 & .52 \\
\hline Residence Russia & .05 & 42 & 11 & 91 \\
\hline Residence Spain & -.05 & 24 & -19 & .85 \\
\hline Residence Sweden & -.03 & .42 & -.06 & .95 \\
\hline Residence United Kingdom (UKK) & -.12 & .16 & -.73 & .47 \\
\hline Residence United States of America (USA) & .03 & .14 & 24 & 81 \\
\hline Education Compulsory schooling & -.02 & .15 & -11 & 91 \\
\hline Education Doctoral study & .16 & .14 & 1.11 & 27 \\
\hline Education School leaving examination & -10 & .16 & .64 & .52 \\
\hline Education University of applied sciences study & .12 & 17 & -73 & .47 \\
\hline Professional Status Freelancer/self-emploved & 21 & .12 & 1.74 & os \\
\hline Professional Status Student & 27 & 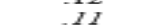 & 2.42 & $02 *$ \\
\hline \multirow{2}{*}{\multicolumn{5}{|c|}{ Interaction effects }} \\
\hline & & & & \\
\hline Risk-taking *Intensity & .07 & .02 & 3.25 & $.00 * * *$ \\
\hline Procactiveness \& Intensity & 15 & 03 & 5.47 & $.00 * * *$ \\
\hline Inmovativeness * Intensith & .06 & 03 & 2.38 & $.02 *$ \\
\hline
\end{tabular}

4 fits the data best, indicating that the influence of risktaking, proactiveness, and innovativeness on opportunity recognition is indeed moderated by gaming intensity (Table 1). Table 2 depicts the estimates from model 4 . It becomes evident that the only few coefficients are significant, despite a very good model determination ( $\mathrm{R} 2=.69$ ). The intercept $(\mathrm{b}$ $=-.67, \mathrm{p} \leq .001)$ shows that the average opportunity recognition is below the average but is increased by gamers frequently playing shooters $(b=.27, p \leq .001)$ and by student gamers $(\mathrm{b}=.27, \mathrm{p} \leq .001)$. The lack of other relevant control variables indicates that opportunity recognition for gamers is not different for genders, ages, residence, and education. Further, the positive interaction effects of risk-taking $(b=.07, p \leq$ $.001)$, proactiveness $(\mathrm{b}=.15, \mathrm{p} \leq .001)$ and innovativeness $(\mathrm{b}=.06, \mathrm{p} \leq .05)$ with intensity illustrate synergies between playing intensity and the entrepreneurial orientation dimensions in increasing opportunity recognition. As depicted in Figures X1, $\mathrm{X} 2$, and $\mathrm{X} 3$, playing games more intensively increase the effect of entrepreneurial orientation on recognizing opportunities in all three dimensions. All three figures illustrate the slopes of each dimension on opportunity recognition for low (mean - $1 \mathrm{SD}$ ), moderate (mean) and high (mean $+1 \mathrm{SD})$ levels of intensity.

\section{Discussion}

Due to the exploratory character of this study, the discussion is structured around the major questions that arose from the results.

\subsection{Why do shooter gamers show increased opportunity recognition?}

A key finding of this study was the interaction affects the shooting genre games have on the prevalence of opportunity recognition cognitive skills. Opportunity recognition was measured via three associated cognitive subscales: scanning and search, association and connection, and evaluation and judgment. This is interesting in several ways. The design and 'play' elements of shooter games require the players to interact and decide within the environment [73] quickly. That is, gamers need to react or evaluate and decide rapidly based on the information provided, which is similar to research findings that have suggested the process of efficient evaluation is necessary for entrepreneurial opportunity recognition [62]. Respondents who play shooters, therefore, may not be more successful in opportunity recognition yet, but the results suggest that these individuals are displaying similar cognitive processing skills to decisively making quick decisions. 
Notwithstanding that causality cannot be assumed, the other way of effect may also be possible. Ventura et al. (2012) [68] found that particular video gaming genre preferences can lead to higher academic performance when mediated by openness and consciousness. Hence, the attributes inherent in opportunity recognition, openness to ideas, conscious evaluation, and quick decision making may lead people with greater opportunity recognition to choose the shooter genre more frequently and play those games more intensively as they fit with their cognitions. Future research could further explore this link by examining across a longitudinal basis. Additionally, further studies could be designed to explore the causal relationships between this game genre, cognitive skills, and entrepreneurship.

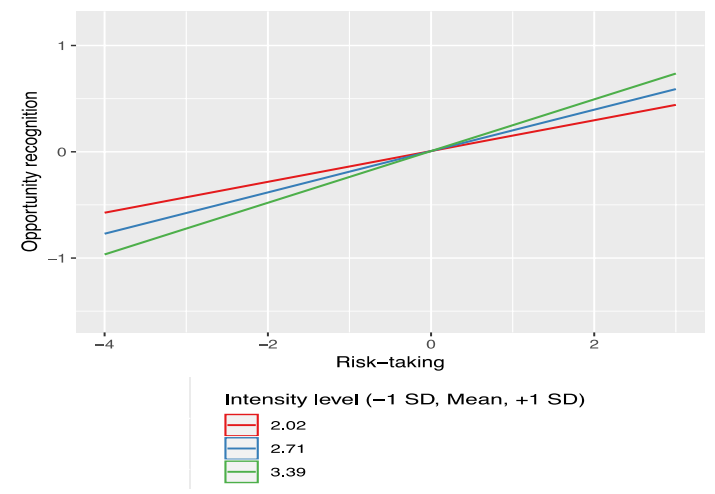

Figure X1. Interaction of risk-taking and opportunity recognition

\subsection{Why do student gamers show increased opportunity recognition?}

Another interesting result of this study was the variations between demographic groups. While the study's sample was designed to capture the perceptions of self-reported gamers, students were found to have a higher likelihood of opportunity recognition skills. Students have been previously found to be less driven by attitudes and to have stronger cognitive skills than non-students [52]. Since opportunity recognition requires high cognitive processing capability (e.g., blending market information with creativity [28; 45; 67]), it becomes evident that this dependence on cognitive skills fits well with the often-found higher cognitive abilities of students. In cooperation with the importance of consciousness in gaming settings [68], it seems that student gamers are well trained in using their cognitive skills and therefore apply their skills in evaluating opportunities or, vice versa, their opportunity recognition skills motivate them to seek opportunities in gaming. The link between student cognitions and the ability to quickly assess opportunities is a promising avenue for future research, as well as how the game design mechanics might enable this type of entrepreneurial activity.

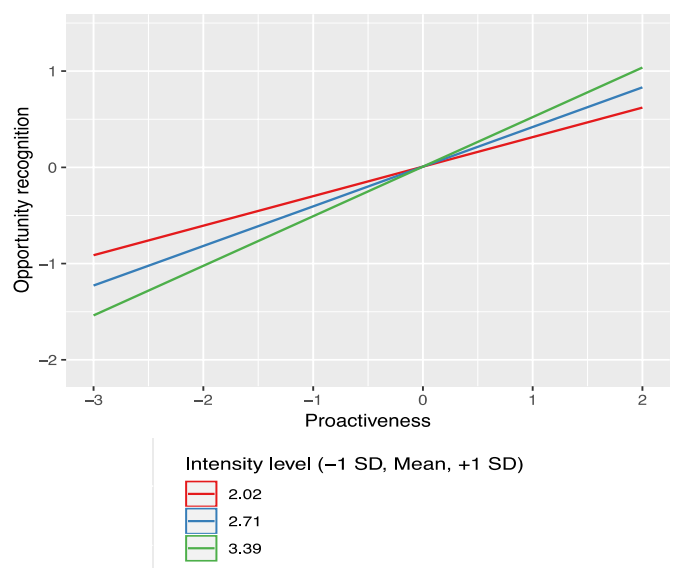

Figure X2. Interaction of proactiveness and opportunity recognition

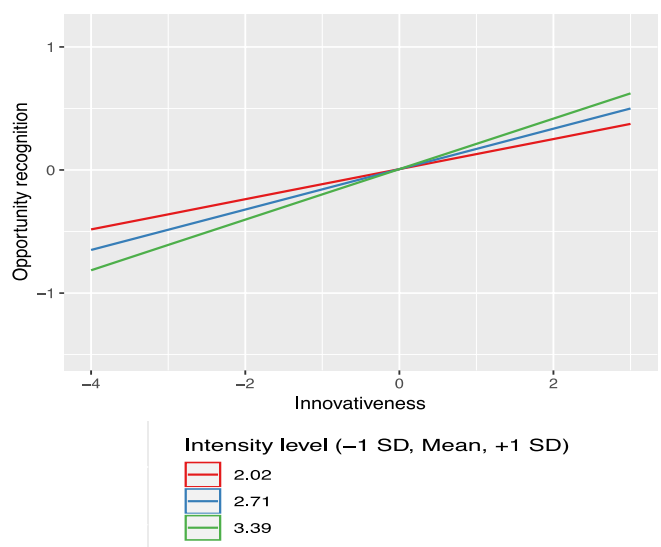

Figure X3. Interaction of innovativeness and opportunity recognition

\subsection{Why is intensity amplifying the effects of entrepreneurial orientation dimensions on opportunity recognition?}

The link between entrepreneurial orientation and opportunity recognition itself, as well as the imprint of individual personality, is well established within the entrepreneurial thinking literature [29]. People act more risk-taking, proactive, and innovative because they are open to new ideas and experiences, producing internal motivation that can help to boost the experienced situation into valuable learning [51]. Since it has been argued that gaming increases consciousness and openness [68], it is likely that gaming intensity supports the beneficial effects of entrepreneurial orientations on opportunity recognition on the same 
personality trait level. In a nutshell, gaming may attract personalities that possess higher entrepreneurial skills. Alternatively, playing games, mainly shooting games, may also sharpen the skills relevant for entrepreneurial thinking and thereof strengthen opportunity recognition. This second implication, however, requires some causality not intended in the present research but is a fruitful avenue for future work.

\section{Conclusions}

This study makes several contributions to the literature and offers several promising avenues for future research. Attempts were made to enhance the generalizability of the study; however, some limitations impinge upon our ability to apply the lessons on a broader scale. Throughout the discussion, we have provided several recommendations to expand this work and to test further the hypotheses put forward. Importantly, the results of this study suggest that there are certain forms of games activities and design options that could unlock the cognitive development of opportunity recognition in the prenascent phases of an entrepreneur. Future studies could expand upon the notion of game genres, the entrepreneurial mindset, and various sample populations to further test this finding. Additionally, capturing the cognitive processing of the pre-nascent entrepreneur is a methodological issue, and this study contributes to the entrepreneurial intent literature. Finally, this study has practical implications for game designers and managers, as it emphasizes the need for gamification strategies to consider the anticipated behavioral outcomes and the influence certain design activities may have on the development of desired cognitive skills.

\section{References}

[1] Aiken, L. S., and West, S. G. Multiple regression: Testing and interpreting interactions. Thousand Oaks, CA, US: Sage Publications, Inc. (1991).

[2] Argawal, R., and Karahanna, E. "Time flies when you're having fun: Cognitive absorption and beliefs about information technology usage." MIS Quarterly. 24(4): 665694. (2000).

[3] Bergkvist, L., and Rossiter, J. R. "The predictive validity of multiple-item versus single-item measures of the same constructs." Journal of Marketing Research. 44(2): 175-184. (2007).

[4] Chandra, Y., Styles, C., and Wilkinson, I. "The recognition of first time international entrepreneurial opportunities." International Marketing Review. 26(1): 3061. (2009).
[5] Chen, M.-H., and Yang, Y.-J. "Typology and performance of new ventures in Taiwan: A model based on opportunity recognition and entrepreneurial creativity." International Journal of Entrepreneurial Behavior \& Research. 15(5): 398-414. (2009).

[6] Christensen, P. S., Madsen, O. O., and Peterson, R. Opportunity Identification: The Contribution of Entrepreneurship to Strategic Management. Denmark: Aarhus University Institute of Management. (1989).

[7] Corbett, A. C. "Learning asymmetries and the discovery of entrepreneurial opportunities." Journal of Business Venturing. 22(1): 97-118. (2007).

[8] Covin, J. G. and Slevin, D. P. "Strategic management of small firms in hostile and benign environments." Strategic Management Journal. 10 (1): 75-87. (1989).

[9] Creswell, J. W. Research design: Qualitative \& quantitative approaches (17. Dr). Thousand Oaks, Calif.: Sage Publications. (2001).

[10] Dai, L., Maksimov, V., Gilbert, B. Anitra and Fernhaber, S. A. "Entrepreneurial orientation and international scope: The differential roles of innovativeness, proactiveness, and risk-taking." Journal of Business Venturing. 29 (4): 511-524. (2014).

[11] Deterding, S. "Eudaimonic design, or: Six invitations to rethink gamification.” In M. Fuchs, S. Fizek, P. Ruffion, \& N. Sharpe (Eds). Rethinking Gamification: 305-331. Lineberg, Germany, Mason Press. (2014).

[12] Deterding, S., Khaled, R., Nacke L.E. and Dixon, D. "Gamification: Toward a Definition." CHI 2011 Gamification Workshop Proceedings. Vancouver. 12-15. (2011)

[13] Dimov, D. "Beyond the Single-Person, Single-Insight Attribution in Understanding Entrepreneurial Opportunities." Entrepreneurship Theory and Practice. 31(5): 713-731. (2007).

[14] Endres, A. M., and Woods, C. R. "The case for more "subjectivist" research on how entrepreneurs create opportunities." International Journal of Entrepreneurial Behaviour \& Research. 13(4): 222-234. (2007).

[15] Fillis, I., and Rentschler, R. "The role of creativity in entrepreneurship." Journal of Enterprising Culture. 18(1): 49-81. (2010).

[16] Fellnhofer, K., Puumalainen, K. and Sjogren, H. "Entrepreneurial orientation and performance - are sexes equal?" International Journal of Entrepreneurial Behavior and Research. 22 (3): 346-374. (2016).

[17] Ferreira, T., Araujo, A., Fernandes, S., and Miguel, I., "Gamification in the workplace: A systematic literature review." In: Rocha Á., Correia A., Adeli H., Reis L., Costanzo S. (eds) Recent Advances in Information Systems and Technologies. WorldCIST 2017. Advances in Intelligent Systems and Computing. vol 571. Springer, Cham (2017).

[18] Fornell, C. and Larcker, D. F. "Evaluating structural equation models with unobservable variables and measurement error." Journal of Marketing Research. 18 (1), 39. (1981). 
[19] Fowler, F. Survey research methods (4th ed.). 2455 Teller Road, Thousand Oaks California 91320 United States: SAGE Publications, Inc. (2009).

[20] Garris, R. and Ahlers, R. "A game-based training model: Development, application, and evaluation." Interservice/Industry Training, Simulation, and Education Conference. (2001).

[21] George, N. M., Parida, V., Lahti, T., and Wincent, J. “A systematic literature review of entrepreneurial opportunity recognition: insights on influencing factors." International Entrepreneurship and Management Journal. 12(2): 309-350. (2016).

[22] Gielnik, M. M., Frese, M., Graf, J. M., and Kampschulte, A. "Creativity in the opportunity identification process and the moderating effect of diversity of information." Journal of Business Venturing. 27(5): 559576. (2012).

[23] Goktan, A. Banu and Gupta, V. K. "Sex, gender, and individual entrepreneurial orientation: Evidence from four countries." International Entrepreneurship and Management Journal. 11 (1): 95-112. (2015).

[24] Gray, P. The research imagination: An introduction to qualitative and quantitative methods. Cambridge: University Press. (2007).

[25] Green, S., and Bavelier, D. "Action video game modify visual selective attention." Letters to Nature. 423: 534-537. (29 May 2003).

[26] Gruber, M., MacMillan, I. C., and Thompson, J. D. "Look Before You Leap: Market Opportunity Identification in Emerging Technology Firms." Management Science. 54(9):1652-1665. (2008).

[27] Guerrero, M. and Pena-Legazkue, I. "The effect of intrapreneurial experience on corporate venturing: Evidence from developed economies." International Entrepreneurship and Management Journal. 9 (3): 397-416. (2013).

[28] Gundry, L. K., Ofstein, L. F., and Monllor, J. "Entrepreneurial Team Creativity: Driving Innovation from Ideation to Implementation." Journal of Enterprising Culture. 24(1): 55-77. (2016).

[29] Gupta, V. K., Niranjan, S., Goktan, B. A. and Eriskon, J. "Individual entrepreneurial orientation role in shaping reactions to new technologies." International Entrepreneurship Management Journal. 12(4): 935-961. (2016).

[30] Hamari, J., Koivisto, J., and Sarsa, H. "Does gamification work? - A literature review of empirical studies on gamification." Proceedings of the $47^{\text {th }}$ Hawaii International Conference on System Sciences (HICSS): 3025-3034. Hawaii. (2014).

[31] Henseler, J., Ringle, C. M., and Sarstedt, M. „A new criterion for assessing discriminant validity in variance-based structural equation modeling." Journal of the Academy of Marketing Science. 43(1): 115-135. (2015).

[32] Huotari, K., and Hamari, J. "A definition for gamification: Anchoring gamification in the service marketing literature." Electronic Markets. 27(1): 21-31. (2017).

[33] Hurley, B. "Everyone loves winning: how Rydges used gamification to double sales.” afr.com. (May 16, 2013).

[34] Ireland, R. D., Webb, J. W., and Coombs, J. E. "Theory and methodology in entrepreneurship research." In D. Ketchen \& D. D. Bergh (Eds.), Research methodology in strategy and management vol. 2: 1-32. (2005).

[35] Jeno, L. M., Grytnes, J.-A. and Vandvik, V. "The effect of a mobile-application tool on biology students' motivation and achievement in species identification: A selfdetermination theory perspective." Computers \& Education. 107: 1-12. (2017).

[36] Kim, C., Jeon, J.-H., and Kim, M.-S. "Identification and Management of opportunities for technology-based services: a patent-based portfolio approach." Innovation: Management, Policy \& Practice. 17(2): 232-249. (2015).

[37] Kollmann, T., Christofor, J. and Kuckertz, A. Explaining individual entrepreneurial orientation: Conceptualization of a cross-cultural research framework. International Journal of Entrepreneurship and Small Business. 4 (3): 325. (2007).

[38] Kreiser, P. M., Marino, L. D., Kuratko, D. F. and Weaver, K. M. "Disaggregating entrepreneurial orientation: the non-linear impact of innovativeness, proactiveness and risk-taking on SME performance." Small Business Economics. 40 (2): 273-291. (2013).

[39] Krueger, N. and Brazeal, D. "Entrepreneurial potential and potential entrepreneurs." Entrepreneurship Theory and Practice. 18(3): 91-104. (1994).

[40] Langkamp Bolton, D. and Lane, M. D. "Individual entrepreneurial orientation: Development of a measurement instrument." Education + Training. 54 (2/3): 219-233. (2012).

[41] Lent, R.W., Brown, S.D., and Hackett, G. "Social cognitive career theory" (pp. 255-311). In D. Brown, L. Brooks, and Associates, Career choice and development (4th $E d$.). San Francisco, CA: Jossey-Bass. (2002).

[42] Little, T. D. The Oxford Handbook of quantitative methods, volume 1: Foundations. Oxford Library of Psychology. Oxford: Oxford University Press USA. (2013).

[43] Lumpkin, G. T. and Dess, G. G. "Clarifying the entrepreneurial orientation construct and linking it to performance." Academy of Management Review. 21(1): 135172. (1996).

[44] Lumpkin, G. T., and Lichtenstein, B. B. "The Role of Organizational Learning in the Opportunity- Recognition Process." Entrepreneurship Theory and Practice. 29(4): 451472. (2005).

[45] Martin, L., and Wilson, N. "Opportunity, discovery and creativity: A critical realist perspective." International Small Business Journal. 34(3): 261-275. (2016).

[46] Mathisen, G. E., and Einarsen, S. "A Review of Instruments Assessing Creative and Innovative Environments 
Within Organizations." Creativity Research Journal. 16(1): 119-140. (2004).

[47] McAllister, K. Game work: Language, power, and computer game culture. University of Alabama Press, Alabama. (2004).

[48] Miller, D. "The correlates of Entrepreneurship in three types of firms." Management Science. 29 (7): 770-791. (1983).

[49] Neck, H. M., and Greene, P. G. "Entrepreneurship education: Known Worlds and New Frontiers." Journal of Small Business Management. 49 (1): 55-70. (2011).

[50] Nunally, J. C., Psychometric theory. 2nd Edition, McGraw-Hill, New York. (1978).

[51] Padilla-Melendez, A., Fernandez-Gamez, M. A., and Molina-Gomez, J. "Feeling the risks: effects of the development of emotional competences with outdoor training on the entrepreneurial intent of university students." International Entrepreneurship and Management Journal. 10 (4): 861-884. (2014).

[52] Peterson, R. A. "On the use of college students in social science research: Insights from a second-order metaanalysis." Journal of Consumer Research. 28(3): 450-461. (2001).

[53] Raftopolous, M. “Towards gamification transparency: A conceptual framework for the development of responsible gamified enterprise systems." Journal of Gaming and Virtual Worlds. 6(2): 159-170. (2014).

[54] Rauch, A., Wiklund, J., Lumpkin, G. T. and Frese, M. "Entrepreneurial orientation and business performance: An assessment of past research and suggestions for the future." Entrepreneurship Theory and Practice. 33 (3): 761-787. (2009).

[55] Roos, J., and Victor, B. "Towards a new model of strategy-making as serious play." European Management Journal. 17: 348-355. (1999).

[56] Ruhi, U. "Level Up Your Strategy: Towards a Descriptive Framework for Meaningful Enterprise Gamification." Technology Innovation Management Review. 5 (8). (2015-01-01).

[57] Ryan, R. M., Rigby, C. S., and Przybylski, A. "The motivational pull of video games: A Self-Determination theory approach." Motivation and Emotion. 30 (4): 344-360. (2006).

[58] Santos, S. C., Caetano, A., Baron, R., and Curral, L., "Prototype models of opportunity recognition and the decision to launch a new venture: Identifying the basic dimensions." International Journal of Entrepreneurial Behaviour \& Research. 21(4): 510-538. (2015).

[59] Schendera, C. F. G. Regressionsanalyse mit SPSS (2. korr. und aktualisierte Aufl.). De Gruyter Studium. München: De Gruyter (2014).

[60] Schutter, B., and Abeele, V. "Designing meaningful play within the psycho-social context of older adults."
Proceedings of the 3rd International Conference on Fun and Games: 84-93 (2010).

[61] Sexton, D. L., and Bowman, N. "The entrepreneur: A capable executive and more." Journal of Business Venturing. 1(1): 129-140. (1985).

[62] Shane, S., and Venkataraman, S. "The promise of entrepreneurship as a field of research." Academy of Management Review. 25(1): 217-226. (2000).

[63] Siegel, P. H., Omer, K. and Agrawal, S. P. "Video simulation of an audit: an experiment in experiential learning theory." Accounting Education. 6 (3): 217-230. (1997).

[64] Statler, M., Heracleous, L., Jacobs, C. "Serious play as a paradox." The Journal of Applied Behavioral Science. 47(2), 236-256. (2011).

[65] Suh, A., Cheung, C., Ahuha, M., and Wagner, C., "Gamification in the workplace: the central role of aesthetic experience." Journal of Management Information Systems. 34(1): 268-305. (2017).

[66] Tang, J., Kacmar, K. Michele and Busenitz, L. "Entrepreneurial alertness in the pursuit of new opportunities." Journal of Business Venturing. 27 (1): 77-94. (2012).

[67] Vaghely, I. P., and Julien, P.-A., "Are opportunities recognized or constructed? An information perspective on entrepreneurial opportunity identification." Journal of Business Venturing. 25(1): 73- 86. (2010).

[68] Ventura, M., Shute, V. \& Kim, Y. J. "Video gameplay, personality and academic performance." Computers \& Education. 58 (4): 1260-1266. (2012).

[69] Vesa, M., and Harviainen, J. "Gamification: Concepts, consequences, and critiques." Journal of Management Inquiry. 28(2): 128-130. (2019).

[70] Wang, Y.-L., Ellinger, A. D., and Wu, Y.-C. J. "Entrepreneurial opportunity recognition: an empirical study of R\&D personnel.” Management Decision. 51(2): 248-266. (2013).

[71] Ward, T. B. "Cognition, creativity, and entrepreneurship." Journal of Business Venturing. 19(2): 173-188. (2004).

[72] Wiklund, J. and Shepherd, D. "Knowledge-based resources, entrepreneurial orientation, and the performance of small and medium-sized businesses." Strategic Management Journal. 24 (13): 1307-1314. (2003).

[73] Wilson, K. A., Bedwell, W. L., Lazzara, E. H., Salas, E., Burke, C. Shawn, Estock, J. L., Orvis, K. L. and Conkey, C. "Relationships between game attributes and learning outcomes." Simulation \& Gaming. 40 (2): 217-266. (2009).

[74] Zichermann, G., and Cunningham, C. "Introduction". Gamification by Design: Implementing Game Mechanics in Web and Mobile Apps (1st ed.). Sebastopol, California: O'Reilly Media. p. xiv.. (August 2011). 